\title{
O projeto pombalino de imposição da língua portuguesa aos índios e a sua aplicação na América meridional*
}

\author{
Elisa Frïhauf Garcia ${ }^{* *}$
}

Na década de 1770, foram fundados dois estabelecimentos de ensino, uma escola e um recolhimento, para a educação da população indígena da Aldeia dos Anjos, localizada no Rio Grande de São Pedro. Tendo como base o Diretório pombalino, o principal objetivo destes estabelecimentos era integrar os índios à sociedade colonial e, para isso, foi imposta a obrigatoriedade da língua portuguesa e a proibição da língua guarani. Este artigo aborda os limites e as implicações desta política lingüística.

Palavras-chave: Política Linguiística - Índios Guarani - Língua Guarani

The Marquis of Pombal's Project for the Imposition of the Portuguese Language on Brazil's Native People and its Application in South America

Two teaching establishmen ts were founded in the 1770s: a school and a secluded camp. Both were geared towards educating the indigenous population of Aldeia dos Anjos, a village located in the territory of Rio Grande de São Pedro. These establishments were based upon the Marquis of Pombal's Directorate, the principal aim

* Artigo recebido em abril de 2007 e aprovado para publicação em maio de 2007.

** Doutora em História pela Universidade Federal Fluminense. Pós-doutoranda em Antropologia na Universidade Estadual de Campinas e bolsista do CNPq. E-mail: elisafg@terra. com.br. 
of which was the integration of the Indians into the colonial society. To this end, knowledge of the Portuguese language was imposed as an obligation for the Native population and the speaking of Guarani was prohibited. The present article deals with the limitations and implications of this linguistic policy.

Keywords: Linguistic Policy - Guaranis Indians - Guarani Language

Le projet du Marquis de Pombal pour l'imposition de la langue portugaise aux indiens et sa mise en oeuvre en Amérique méridionale

Pendant les années 1770, on connut la fondation de deux institutions - une école et un abri - pour l'éducation des peuples indigènes d'Aldeia dos Anjos, au Rio Grande de São Pedro. Ayant comme support le Diretório du Marquis de Pombal, le principal but de ces institutions était d'intégrer les indigènes à la société coloniale. Pour ce faire, on a imposé la pratique de la langue portugaise ainsi que la prohibition de la langue guarani. Cet article approche les limites et les implications de cette politique linguistique.

Mots-clés: Politique Linguistique - Indiens Guaranis - Langue Guarani

Em meados do século XVIII, o ministro Sebastião José de Carvalho e Melo, futuro Marquês de Pombal, elaborou uma série de medidas visando integrar as populações indígenas da América à sociedade colonial portuguesa. Estas medidas foram sistematizadas no Diretório que se deve observar nas povoações dos índios do Pará e do Maranhão enquanto sua majestade não mandar o contrário, publicado em 3 de maio de 1757 e transformado em lei por meio do alvará de 17 de agosto de 1758.

O Diretório tinha como objetivo principal a completa integração dos índios à sociedade portuguesa, buscando não apenas o fim das discriminações sobre estes, mas a extinção das diferenças entre índios e brancos. Dessa forma, projetava um futuro no qual não seria possível distinguir uns dos outros, seja em termos físicos, por meio da miscigenação biológica, seja em termos comportamentais, por intermédio de uma série de dispositivos de homogeneização cultural.

Como um dos elementos viabilizadores deste futuro, em que não seria possível distinguir brancos de índios, o Diretório enfatizava a necessidade da realização de casamentos mistos, assim como ordenava que os filhos gerados nestas uniões fossem considerados mais capacitados que os colonos brancos para ocupar cargos administrativos nas antigas aldeias indígenas transforma- 
das em vilas e lugares portugueses. ${ }^{1}$ Proibia, por outro lado, o hábito bastante disseminado de se chamarem os índios de "negros da terra" ou simplesmente "negros". ${ }^{2}$ Este hábito, por sua vez, exemplifica o lugar social ao qual eram remetidos os índios, ao associá-los com a cor dos escravos africanos e seus descendentes.

Os instrumentos para a extinção destas diferenças são mais claros em alguns parágrafos do Diretório, embora perpassem todo o documento. Neste artigo, destaco a imposição do uso obrigatório do idioma português, que deveria ser viabilizado por intermédio das escolas fundadas para educar os índios. No Diretório há um parágrafo dedicado especificamente ao tema, no qual a imposição da autoridade do colonizador aparece como derivada da implantação do seu idioma às populações "conquistadas". Neste parágrafo, foram desenvolvidas e articuladas três principais idéias sobre o tema. Primeiramente, a percepção de acordo com a qual o uso do idioma nativo estava relacionado aos costumes tribais, em que um reforçava o outro. Em segundo, que a adoção do idioma civilizado redundaria na civilização dos costumes. Em terceiro, que a imposição da "língua do príncipe" acarretaria a sujeição dos povos conquistados. Conforme o texto do Diretório:

Sempre foi máxima inalteravelmente praticada em todas as nações, que conquistaram novos domínios, introduzir logo nos povos conquistados o seu próprio idioma, por ser indisputável, que este é um dos meios mais eficazes para desterrar dos povos rústicos a barbárie dos seus antigos costumes; e ter mostrado a experiência, que ao mesmo passo, que se introduz neles o uso da língua do príncipe, que os conquistou, se lhes radica também o afeto, a veneração, e a obediência ao mesmo príncipe. Observando pois todas as nações polidas do mundo este prudente, e sólido sistema, nesta conquista se praticou tanto pelo contrário, que só cuidarão os primeiros conquistadores estabelecer nela o uso da língua, que chamaram geral; invenção verdadeiramente abominável, e diabólica, para que privados os índios de todos aqueles meios, que os podiam civilizar, permanecessem na rústica, e bárbara sujeição, em que até agora se conservavam. Para desterrar este perniciosíssimo abuso, será um

1 "Diretório que se deve observar nas povoações dos índios do Pará e do Maranhão enquanto sua majestade não mandar o contrário", in Rita Heloísa de Almeida, O Diretório dos índios: um projeto de civilização no Brasil do século XVIII, Brasília, Editora da Universidade de Brasília, 1997, p. 371 e segs. (Doravante citado apenas como Diretório). Diretório, parágrafos 84 e 89.

${ }^{2}$ Diretório, parágrafo 10, in Rita Heloísa de Almeida, op. cit. Devido à prática de utilização da mão-de-obra indígena estabelecida em algumas regiões da Colônia, passou-se a designar os índios como negros da terra, para diferenciá-los dos escravos de origem africana. Ver: John Monteiro, Negros da terra: índios e bandeirantes nas origens de São Paulo, São Paulo, Companhia das Letras, 1994. 
dos principais cuidados dos diretores, estabelecer nas suas respectivas povoações o uso da língua portuguesa, não consentindo por modo algum, que os meninos, e meninas, que pertencem as escolas, e todos aqueles índios, que forem capazes de instrução nesta matéria, usem da língua própria das suas nações, ou da chamada geral; mas unicamente da portuguesa, na forma, que Sua Majestade tem recomendado em repetidas ordens, que até agora se não observaram com total ruína espiritual, e temporal do Estado. ${ }^{3}$

No século XVIII, no entanto, além das populações indígenas, vários outros segmentos sociais não utilizavam o português para se comunicar, mas sim a língua geral, ${ }^{4}$ falada por moradores de várias regiões da Colônia. Esta situação levou a Coroa a buscar meios de impor o português nos seus domínios americanos. ${ }^{5}$ Além dos idiomas indígenas, nesta época também vigoravam línguas africanas, amplamente usadas pelos escravos e seus descendentes. Apesar de não terem sido tão intensamente utilizadas como as línguas gerais indígenas e, tampouco, objeto de uma política específica de extinção neste período, as línguas africanas também significavam entraves ao projeto de exclusividade do português. ${ }^{6}$

A perspectiva de impor aos índios o uso da língua portuguesa, no entanto, tinha um objetivo bem claro neste período: buscava transformá-los em vassalos iguais aos demais colonos. Isto se fazia necessário num momento no qual foram intensificados os conflitos territoriais entre Portugal e Espanha, acarretando a necessidade de o Rei de Portugal possuir um contingente populacional suficiente para habitar as suas fronteiras, garantindo assim a permanência dos seus domínios.

\footnotetext{
${ }_{3}^{3}$ Diretório, parágrafo 6, in Rita Heloísa de Almeida, op. cit.

${ }^{4}$ O termo "língua geral" é bastante genérico e parece não ter significado uma língua específica, mas sim línguas baseadas no tupi-guarani que, ao longo da experiência colonial, adquiriram traços regionais bastante diferenciados. No processo da disseminação de seu uso por amplos segmentos sociais e da normalização gramatical, estas línguas passaram por um profundo processo de modificação. Tornaram-se, então, não linguagens indígenas, mas, segundo John Monteiro, um "dialeto colonial”. John Monteiro, “Tupis, tapuias e historiadores. Estudos de história indígena e do indigenismo", Campinas, São Paulo, Unicamp (tese de livre docência), 2001, p. 63. Sobre o tema da formação da língua geral, principalmente na região norte, ver: José Ribamar Bessa Freire, "Rio Babel - a história das línguas na Amazônia", Rio de Janeiro, EdUERJ, 2004.

${ }^{5}$ Luiz Carlos Villalta, "O que se fala e o que se lê: língua, instrução e leitura", in Laura de Mello e Souza, História da vida privada no Brasil: cotidiano e vida privada na América portuguesa, São Paulo, Companhia das Letras, 1997, p. 334.

${ }^{6}$ José Honório Rodrigues, “A vitória da língua portuguesa no Brasil colonial”, Humanidades, vol. 1, n. 4. Brasília, 1983, p. 29 e segs.
} 
Segundo Ângela Domingues, o uso da língua portuguesa seria empregado como um critério nas disputas de fronteira entre Portugal e Espanha, baseadas no princípio do uti possidetis. ${ }^{7}$ A língua portuguesa teria, então, dois papéis principais: interferiria na identidade dos índios, tentando transformá-los em portugueses, o que, por sua vez, comprovaria a efetiva ocupação lusitana daquelas terras. ${ }^{8}$

Para obter a integração dos índios e a sua transformação em súditos portugueses iguais aos demais colonos, era necessário transformar o estatuto jurídico e social que os índios tinham na sociedade de Antigo Regime. Esta sociedade possuía como um dos seus pilares a noção de pureza racial, sendo esta concepção de raça fruto de uma combinação entre ancestralidade e crenças religiosas. ${ }^{9}$ Antes da experiência colonial, não existia em Portugal a noção de raça vinculada ao fenótipo. No entanto, no desenrolar da colonização ultramarina, a escravidão se afirmou enquanto instituição social e foi, paulatinamente, sendo associada à cor do escravo, em grande medida negro e, em menor medida, índio. ${ }^{10}$ Dessa forma, a sociedade colonial deu origem a novos critérios de classificação social, os quais começaram a levar em conta o fenótipo dos indivíduos, relacionando-o ao lugar social que eles ocupavam. Estes novos critérios, porém, foram integrados dentro da lógica de classificação preexistente. Assim, à noção de raça baseada na ancestralidade e nas crenças religiosas, agregou-se um outro elemento: o fenótipo, enquanto definidor de hierarquia social. Da combinação destes critérios originou-se uma série

\footnotetext{
${ }^{7} \mathrm{O}$ princípio do uti possidetis adotado no Tratado de Madri previa que, na demarcação dos limites territoriais, caberia a cada Coroa ibérica as terras por elas efetivamente ocupadas.

${ }^{8}$ Ângela Domingues, Quando os índios eram vassalos: colonização e relações de poder no Norte do Brasil na segunda metade do século XVIII, Lisboa, Comissão Nacional para as Comemorações dos Descobrimentos Portugueses, 2000, p. 212.

${ }^{9}$ Ronaldo Vainfas, "Colonização, miscigenação e questão racial: notas sobre equívocos e tabus da historiografia brasileira", Tempo, vol. 4, n. 8, Rio de Janeiro, 1999, p. 7-22.

10 Segundo Evaldo Cabral de Mello, em seu estudo sobre a investigação genealógica à qual eram submetidos os candidatos para o ingresso nas ordens militares, no sistema de classificação das "raças infectas" do período colonial, a ascendência indígena era a menos restritiva, se comparada à negra, judaica ou moura. No entanto, como frisa o autor, tratava-se de ascendência e não de índios de "quatro costados". Ou seja, a ascendência indígena era mais facilmente tolerável, embora esta tolerância não se aplicasse aos que fossem reconhecidos como "realmente" índios, favorecendo apenas os seus descendentes "mestiços". Evaldo Cabral de Mello, O nome e o sangue, Rio de Janeiro, Topbooks, 2000, p. 27-28, 115-116.
} 
de gradações que sugeriam o lugar ocupado pelas pessoas e/ou grupos na hierarquia social. ${ }^{11}$

Ao tentar erradicar as especificidades dos diferentes grupos indígenas, Sebastião José de Carvalho e Melo buscava, por meio do Diretório, criar uma homogeneidade entre os seus súditos, na qual o compartilhamento do mesmo idioma tinha um papel fundamental. No entanto, este projeto encontrou resistência tanto por parte dos colonos como dos índios. Ao voltar-se contra as línguas indígenas e pôr em prática uma política agressiva contra estas, acabou por transformá-las, conforme se verá, num elemento definidor da identidade da população indígena estabelecida na fronteira meridional da América portuguesa.

\section{As escolas indígenas nos confins do Império Português}

As tentativas de demarcação do Tratado de Madri e as conseqüentes políticas de atração da população missioneira para o território do Rio Grande de São Pedro ocasionaram um considerável deslocamento dos guaranis para as terras portuguesas, cujo número total é estimado em 3 mil pessoas. Num primeiro momento, os missioneiros ficaram estabelecidos em Rio Pardo, na aldeia de São Nicolau. Após alguns anos, em 1762, a maior parte destes índios foi transferida para as margens do rio Gravataí, onde foi fundada a aldeia de Nossa Senhora dos Anjos. ${ }^{12}$ Apesar de não ter sido a única aldeia indígena existente nessa época no Rio Grande, a de Nossa Senhora dos Anjos tornouse a mais importante tanto em termos numéricos, pois reunia a maior parte da população guarani oriunda dos Sete Povos, quanto em termos políticos, porque ali a legislação pombalina foi aplicada com maior rigor. ${ }^{13}$

\footnotetext{
${ }^{11}$ Stuart Schwartz, Segredos internos: engenhos e escravos na sociedade colonial, 1550-1835, São Paulo, Companhia das Letras, 1998, p. 209-210. Para Schwartz, apesar de estas diferenças terem também se enraizado em Portugal, foi nos domínios ultramarinos que estas se fizeram mais importantes, sendo os colonos os seus principais defensores. Stuart Schwartz. "Brazilian ethnogenesis: mestiços, mamelucos, and pardos", in Serge Gruzinski et al. Le nouveau monde: mondes nouveaux l'expérience americaine, Paris, Editions Recherches sur les Civilisations; École des Hautes Études en Sciences Sociales, 1996, p. 19.

${ }^{12}$ Após a implementação da legislação pombalina, a Aldeia foi transformada em uma vila portuguesa, conforme especificado no parágrafo 2 do Diretório. No entanto, apesar de ter o estatuto de uma vila, continuava sendo mencionada pelos contemporâneos como aldeia e também como povoação ou povo.

${ }^{13}$ Sobre a aplicação do Diretório na Aldeia dos Anjos, ver: Protásio Paulo Langer, A aldeia de Nossa Senhora dos Anjos: a resistência do Guarani-Missioneiro ao processo de dominação do sistema colonial luso (1762-1798), Porto Alegre, EST, 1997, p. 78 e segs.
} 
De acordo com o previsto no Diretório, foram criados nesta Aldeia, na década de 1770, uma escola em forma de colégio para os meninos e um recolhimento para as meninas, funcionando ambos por, aproximadamente, três décadas. Durante este período, foi produzida uma documentação relativamente completa sobre tais estabelecimentos de ensino. ${ }^{14}$ Dentre a documentação, as fontes mais importantes para o entendimento da escola e do recolhimento são uma série de regras chamadas de regimes, elaboradas pelo governador do Continente, José Marcelino de Figueiredo ${ }^{15}$ a fim de sistematizar o seu funcionamento.

Para o ingresso no recolhimento, a idade mínima era de 6 anos e a máxima, 12, e o número de reclusas não poderia ultrapassar 50. O seu dia era dedicado às orações e ao aprendizado e exercício dos trabalhos domésticos. Ao nascer do sol, deveriam se levantar e fazer a higiene pessoal, seguindo depois para as orações. Após as rezas, as meninas índias iriam para o trabalho, que poderia ser de costura ou de fiação e tecelagem. Então jantariam, teriam um tempo de repouso e retornariam ao trabalho. Depois teriam a ceia, seguida novamente de orações, após as quais deveriam se recolher. Segundo o regimento, dois eram os objetivos a serem alcançados com as meninas: a aptidão na língua portuguesa, não sendo permitido falarem o guarani, e o aprendizado de todos os serviços domésticos necessários ao bom funcionamento de uma casa. ${ }^{16}$

Na escola, por sua vez, os meninos também tinham o seu dia rigidamente organizado, no qual possuíam um horário específico para cada atividade. Deveriam acordar pela manhã, fazer a higiene pessoal e almoçar. Após o almoço, permaneceriam das oito às onze na escola, na qual aprenderiam a falar, ler e escrever em português, a rezar e argumentar. Jantariam ao meio-dia e teriam descanso até as duas horas, quando retornariam para a escola e lá ficariam até as cinco, exceto no verão, quando entrariam às três e sairiam às seis. Após

\footnotetext{
${ }^{14}$ Uma parte considerável desta documentação foi publicada no livro: Os índios D'Aldeia dos Anjos: Gravataí século XVIII, Arquivo Histórico do Rio Grande do Sul, Porto Alegre, EST, 1990.

${ }^{15}$ Registro de uma instrução dada pelo Senhor Brigadeiro Governador de como se há de reger o novo recolhimento. Vila Nova dos Anjos, 2 de fevereiro de 1778, p. 31-32; Registro de uma portaria do senhor brigadeiro governador. Vila Nova dos Anjos, 30 de setembro de 1776, p. 26; Registro de umas ordens que o senhor brigadeiro governador desta capitania foi servido dar para se observarem na escola desta vila na forma seguinte. Vila Nova dos Anjos, 11 de agosto de 1777, p. 26-27, in Os indios D'Aldeia dos Anjos..., op. cit.

${ }^{16}$ Registro de uma instrução dada pelo Senhor Brigadeiro Governador de como se há de reger o novo recolhimento. Vila Nova dos Anjos, 2 de fevereiro de 1778, parágrafos $5^{\circ}$ e 6 , $^{\circ}$ in $O s$ indios D’Aldeia dos Anjos..., op. cit., p. 31.
} 
as aulas, fariam suas orações, ceariam e deveriam se recolher. Nas semanas em que não houvesse feriado, teriam um dia de sueto. ${ }^{17}$ Neste dia, poderiam receber a visita de seus familiares do meio-dia às duas, mas apenas poderiam se comunicar com estes em português. No dia de sueto e nos feriados santos, o mestre poderia escolher entre os seus alunos alguns que considerasse mais aplicados, aos quais concederia licença para irem visitar os pais. Se algum destes meninos cometesse algum tipo de desordem na Aldeia, o mestre deveria ser informado, para não lhes conceder mais licença. Os sábados e os domingos eram destinados às atividades religiosas. A limpeza e a organização do espaço da escola ficariam a cargo dos meninos que, em sistema de rodízio, deveriam passar, cozinhar e varrer para o coletivo. Enquanto estivessem na escola, os alunos deveriam ser vigiados para respeitarem rígidos padrões de limpeza e higiene pessoal e também para, em hipótese alguma, falarem a língua guarani. No regimento estava previsto um castigo para o menino que falasse o guarani e o perdão para quem o delatasse. ${ }^{18}$

De qualquer forma, obrigar os alunos a falarem unicamente o português não era possível, a se dar crédito aos relatos elaborados pelos moradores e à documentação produzida pela burocracia estatal, nos quais se afirma a incapacidade de os índios se expressarem neste idioma. ${ }^{19}$ De acordo com Bernardo José Pereira, estancieiro estabelecido na região, os padres da paróquia da vila dos Anjos não conheciam a língua guarani. Na visão do autor, isto dificultava que os índios, principalmente os mais velhos, se confessassem, pois não sabiam falar português e tampouco demonstravam interesse em aprendê-lo. ${ }^{20}$

Convém lembrar que as crianças deveriam ser enviadas aos estabelecimentos de ensino com, no mínimo, 6 anos, já tendo adquirido o domínio

${ }^{17}$ Termo com o qual era designado o dia de folga.

${ }^{18}$ Registro de umas ordens que o Senhor Brigadeiro Governador desta capitania foi servido dar para se observarem na escola desta vila. Vila Nova dos Anjos, 11 de agosto de 1777, in $O s$ indios D'Aldeia dos Anjos..., op. cit., p. 26-27.

${ }^{19}$ O Governador Sebastião Cabral da Câmara, em 1784, criticava severamente os índios da Aldeia pela ausência de "civilização" nos seus costumes, principalmente por estarem há mais de três séculos vivendo entre os luso-brasileiros sem, no entanto, aprenderem o português. Cópia das instruções, que formalizou o Senhor Brigadeiro Governador para auxílio do regime do Comandante da Povoação de Nossa Senhora dos Anjos o Tenente da Cavalaria Auxiliar Antônio José Machado. Rio Grande, 14 de janeiro de 1784, in Os índios D’Aldeia dos Anjos..., op. cit., p. 76.

${ }^{20}$ Carta de Bernardo José Pereira, sem lugar, data, nem destinatário, com informações acerca dos índios Guarani do Rio Grande do Sul. Biblioteca Nacional, Rio de Janeiro (BNRJ), Ms $7,3,48$. 
do idioma guarani enquanto residiam com sua família. Portanto, se os índios mais velhos apenas falavam guarani e as crianças, após freqüentarem a escola, eram bilíngües, é certo que iriam utilizar o guarani, sob pena de não poderem mais se comunicar com a sua família.

Uma parte importante das idéias que orientavam a educação das crianças índias era consoante com as concepções mais amplas vigentes na sociedade colonial sobre este tema. Assim, enquanto na escola os meninos eram ensinados a "falar português, a ler, escrever, rezar e argumentar", as meninas eram iniciadas "na doutrina cristã, e os serviços todos de uma casa". ${ }^{21} \mathrm{O}$ pressuposto de uma educação diferenciada segundo o sexo se materializava na localização dos alunos em espaços de natureza diferente, cabendo aos meninos a escola e às meninas o recolhimento. $\mathrm{O}$ recolhimento era uma típica instituição de ensino para mulheres no período colonial. Apesar de não ser um convento, pois as reclusas não faziam votos, o tipo de vida nos recolhimentos era conventual, sendo permitido apenas o mínimo de contato com o mundo exterior. ${ }^{22}$ Já a escola não significava o isolamento dos meninos, pois possuíam maior liberdade para deixá-la durante os dias santos e de sueto, assim como para receberem visitas.

Os índios, no entanto, não deveriam permanecer por muito tempo na escola. Logo que soubessem ler e escrever, contar, rezar a doutrina cristã e falar o português, eles deveriam deixar o colégio, para dar lugar a outros. Dessa forma, os alunos não receberiam uma educação muito aprofundada e, tão logo fossem considerados aptos nessas matérias, sairiam da escola. ${ }^{23}$

Além destes dois estabelecimentos para o ensino dos índios, o Marquês do Lavradio, na qualidade de vice-rei, ainda requisitou ao governador o envio de 15 ou 16 índios à capital para aprenderem alguns ofícios. Dentre estes índios, o vice-rei solicitou ao governador que apontasse quais eram filhos de

\footnotetext{
${ }^{21}$ Registro de umas ordens que o Senhor Brigadeiro Governador desta capitania foi servido dar para se observarem na escola desta vila na forma seguinte. Vila Nova dos Anjos, 11 de agosto de 1777, p. 27; Registro de uma instrução dada pelo Senhor Brigadeiro Governador de como se há de reger o novo recolhimento. Vila Nova dos Anjos, 2 de fevereiro de 1778, parágrafo 6, p. 31, in Os indios D'Aldeia dos Anjos..., op. cit.

${ }^{22}$ Maria Beatriz Nizza da Silva, Cultura no Brasil colônia, Petrópolis, Rio de Janeiro, Vozes, 1981, p. 71.

${ }^{23}$ Cópia de uma carta escrita pelo oficial das ordens do Senhor Brigadeiro Governador do Continente ao capitão comandante desta vila em que fala respeito ao regime que deve obrar dito comandante com o recolhimento e escola destes índios. Vila dos Anjos, 26 de setembro de 1780, in Os indios D'Aldeia dos Anjos..., op. cit., p. 37.
} 
principais, para que tivesse ciência. ${ }^{24}$ Este tipo de preocupação aponta para a prática de valorização e reprodução das elites indígenas, estratégia utilizada para tentar captar as lideranças como aliadas nas políticas coloniais. Conforme Maria Regina Celestino de Almeida, a Coroa Portuguesa empreendeu uma política de enobrecimento das lideranças indígenas, a fim de utilizá-las como viabilizadoras da integração dos índios à sociedade colonial. ${ }^{25}$

Apesar de terem sido alvo de projetos de cooptação e de seu estatuto terse modificado ao longo dos contatos, as lideranças indígenas, segundo parece, mantiveram sua capacidade de chefia, sendo vistas pelos índios como representantes de seus interesses, o que era o principal elemento mantenedor de sua autoridade. Mantiveram, em muitos casos, uma capacidade de autonomia e, conseqüentemente, de se oporem a projetos coloniais que não percebiam como vantajosos. Esta capacidade de autonomia se intensificava nas regiões de fronteira, como é o caso do Continente de São Pedro, onde a obtenção de alianças com as populações indígenas era percebida como um aspecto importante para o domínio territorial por meio da sua transformação em vassalos do rei português. ${ }^{26}$ Dessa forma, havia uma política de "bom tratamento" dos índios, visando à sua permanência em terras lusitanas. A perda da aliança com as populações indígenas acarretaria dois problemas: a diminuição dos vassalos portugueses e um incremento populacional do lado espanhol. ${ }^{27}$ Ao propor um projeto de mudança espacial da Aldeia, Bernardo José Pereira apontava que era preciso "primeiro que tudo persuadir os caciques: esta Excelentíssimo Senhor é a mais dificultosa empresa”. ${ }^{28}$ Assim, para Pereira, qualquer tentativa de mudança passaria, necessariamente, pela autorização dos caciques, algo não muito fácil de se conseguir.

\footnotetext{
${ }^{24}$ Capítulo de uma carta do Ilmo. e Exmo. Sr. Marquês do Lavradio, escrita ao governador interino Antônio da Veiga de Andrade. Rio de Janeiro, 14 de março de 1771. BNRJ, Ms 9, 4, 13 , p. $115 \mathrm{v}$.

${ }^{25}$ Maria Regina Celestino de Almeida, Metamorfoses indígenas: identidade e cultura nas aldeias coloniais do Rio de Janeiro, Rio de Janeiro, Arquivo Nacional, 2003, p. 150.

26 Ângela Domingues, op. cit., p. 232.

${ }^{27} \mathrm{O}$ vice-rei, Marquês do Lavradio, em carta ao governador do Rio Grande, José Marcelino de Figueiredo, ordenava o melhor tratamento possível aos índios missioneiros, para que estes vissem como eram mais bem tratados pelos portugueses do que pelos espanhóis, preferindo migrarem para o continente e, dessa forma, seria: "natural que se passem todos para os Domínios de d’El Rei meu Senhor Fidelíssimo, vindo desta sorte a diminuírem das forças dos Espanhóis e aumentarmos as nossas", Carta do vice-rei, Marquês do Lavradio, ao governador do Rio Grande, José Marcelino de Figueiredo, Rio de Janeiro, 2 de março de 1771, Arquivo Nacional, Rio de Janeiro, AP-41 A, microfilme 024-97, RD 2.52.
}

28 Carta de Bernardo José Pereira..., BNRJ, Ms 7, 3, 44. 
As idéias sobre a educação dos índios, sobretudo dos filhos de principais, vinculavam-se ao amplo projeto do Diretório de formação de indivíduos aptos a ocuparem cargos públicos de acordo com o previsto na lei. No entanto, os resultados deste projeto são de difícil averiguação. Não é possível afirmar que os índios, após saírem da escola, não tenham sido utilizados em tais funções. Um dos maiores empecilhos para esta integração eram os preconceitos subjacentes na elite local acerca da "natureza" dos índios. ${ }^{29}$ Porém, apenas estes preconceitos não são suficientes para explicar a possível ausência de índios na administração local. O principal obstáculo ao esclarecimento desta questão é o próprio projeto de miscigenação dos índios com a população de origem lusitana. O sucesso deste projeto não deixa vestígios documentais. Um indivíduo de nome português, versado neste idioma e que tenha adotado, por escolha ou nascimento, hábitos "civilizados", não poderá ser diferenciado, pelo pesquisador, dos demais colonos na documentação legada pela burocracia colonial.

Por tratar-se de índios oriundos das missões jesuíticas espanholas, era de se esperar que falassem, além do guarani, também o castelhano. Para o governo espanhol, o ideal seria que os índios soubessem e utilizassem a língua castelhana. No entanto, diante da sua impossibilidade, previa que as populações nativas pudessem ser educadas e catequizadas nos seus respectivos idiomas, às quais seria facultado e até incentivado o aprendizado do castelhano, porém não poderiam estar sujeitas a nenhum tipo de coerção para este fim ${ }^{30}$. Após a expulsão dos jesuítas, em 1767, a política lingüística da Coroa espanhola mudou de direção, passando a prever a obrigatoriedade da língua espanhola em seu Império. Para os Trinta Povos do Paraguai, foram estabelecidas medidas similares às adotadas por Pombal, que tiveram como modelo o Diretório dos Índios. ${ }^{31}$

\footnotetext{
${ }^{29}$ A maioria dos moradores do continente não estava de acordo com as medidas pombalinas de transformação dos índios em vassalos, pois considerava isto inviável devido às suas concepções sobre a "natureza" dos índios, que os fazia inferiores aos brancos e incapazes para o aprendizado intelectual. Um exemplo deste tipo de pensamento pode ser encontrado na seguinte memória: Sebastião Francisco Bettamio, "Notícia particular do Continente do Rio Grande do Sul" [1780], Revista do Instituto Histórico e Geográfico Brasileiro, tomo 31, Rio de Janeiro, $3^{\circ}$ trimestre de 1858, 2.ed. 1930, p. 222 e segs.

${ }^{30}$ Recopilacion de Leyes de los Reinos de las Indias, Madri, Consejo de la Hispanidad, 1943, 3 vols., Ley 4, tit. 13, lib. 1 \& ley 18, tit. I, lib. 6.

${ }^{31}$ Ernesto Maeder, "El modelo portugues y las instruciones de Bucarelli para las misiones de guaranies", Estudos Ibero-Americanos, ano 13, n. 2, Porto Alegre, 1987, p. 135 e segs. Sobre estas medidas e a importância concedida à imposição da língua espanhola, ver: Guillermo Wilde, "Segregación o asimilación? La política indiana en América meridional a fines del período colonial”, Revista de Indias, vol. LIX, n. 217, Madri, 1999, p. 619-643.
} 
Nas reduções havia escolas primárias e de um ensino que era concebido como superior. Os meninos considerados mais aptos pelos jesuítas, geralmente filhos de principais, eram enviados à escola para aprenderem a ler e escrever na língua nativa, além de contar. Depois deveriam aprender o espanhol e o latim, o que na prática geralmente não ocorria. Os índios que demonstrassem alguma habilidade, após este ensino primário, poderiam aprender música vocal, instrumental e danças. Além disso, também eram iniciados em ofícios mecânicos, tal como escultura, pintura, mecânica, carpintaria, marcenaria, entre outros.

Ao serem aldeados na Aldeia de Nossa Senhora dos Anjos, portanto, os índios já tinham um contato anterior e duradouro não apenas com a escola, mas também com outras práticas consideradas "civilizadas", tais como a agricultura sedentária e a organização familiar nuclear. Esta experiência anterior possivelmente deve ter facilitado a instituição da escola na Aldeia, pois entre os guaranis missioneiros já existia a prática de os meninos freqüentarem a escola, podendo esta ser vista, então, como uma continuidade da realidade das missões. No entanto, esta experiência anterior também deve ter dificultado o estabelecimento do recolhimento para as meninas índias, introduzindo uma novidade em relação à sua vivência nas reduções.

O ensino ministrado no recolhimento da Aldeia era diferente do aplicado às demais meninas da Colônia, assim como não estava de acordo com o previsto no Diretório. A diferença no projeto de educação das índias na Aldeia dos Anjos e das demais meninas da Colônia estava no aprendizado de ler, escrever e contar. Enquanto nos demais recolhimentos estas matérias deveriam ser ministradas às meninas, ${ }^{32} \mathrm{o}$ regimento sobre o recolhimento das índias não previa tal tipo de aprendizado. Todo o tempo era destinado às orações e ao exercício das lides domésticas, não existindo uma mestra de gramática, como existia um mestre para os meninos. Os colonos que comentaram sobre os estabelecimentos de ensino para os índios não fizeram qualquer referência ao estudo da leitura e da escrita no recolhimento.

O Diretório, no entanto, previa que as índias, além de aprenderem a doutrina cristã e os "mistérios próprios daquele sexo", ${ }^{33}$ deveriam ser ensinadas a ler e escrever, mas não a contar. É importante notar que se o recolhimento não estava de acordo com o estipulado pelo Diretório, era, porém, mais próximo

${ }^{32}$ Maria Beatriz Nizza da Silva, op. cit., p. 75.

${ }^{33}$ Diretório, parágrafo 7, in Rita Heloísa de Almeida, op. cit. 
da concepção de educação existente nas reduções. Estas tinham um sistema educacional relativamente sofisticado para os meninos, mas não existia algo semelhante para as meninas, ${ }^{34}$ As índias eram retiradas do convívio da sua família para serem educadas, porém esta educação não abarcava nem a leitura, nem a escrita, nem a aritmética, mas sim as tradicionais atividades do trabalho feminino. Pode-se, portanto, cogitar que a subtração do ensinamento da leitura e da gramática no recolhimento implantado na Aldeia tenha sido uma adaptação à realidade dos missioneiros, visando evitar conflitos advindos do desrespeito de uma divisão sexual já consolidada das atividades escolares.

Por outro lado, ao fazer esta concessão, o governo do continente não se desviou do projeto principal do Diretório relativo à educação das meninas índias, cujo objetivo era a realização do maior número possível de casamentos mistos. As reclusas podiam receber propostas de casamento que deveriam ser comunicadas ao governador. Este avaliaria a qualidade do pretendente e, se fosse do seu agrado, permitiria a união e proporcionaria ao casal enxoval e dote. No momento de seu casamento, as meninas já teriam uma boa parte do seu enxoval pronto, pois durante o período em que estavam no recolhimento dedicavam boa parte do tempo à sua confecção.

No caso dos casamentos mistos também é difícil averiguar a sua efetiva realização, pois a ascendência indígena era muitas vezes omitida nos registros matrimoniais. Nas prestações de contas efetuadas pela Real Fazenda constam dotes pagos às índias. No entanto, estes foram poucos, deixando a impressão de que o governo metropolitano não atingiu a grande quantidade de consórcios que gostaria. ${ }^{35}$

Em 1800 e 1801, o recolhimento e a escola, respectivamente, tiveram as suas atividades encerradas e seus prédios foram vendidos, atendendo, segundo a versão oficial, à diminuição do número de alunos em consequiência do esvaziamento indígena da Aldeia. Apesar do efetivo funcionamento da escola e do recolhimento por mais de duas décadas, a política de substituição da língua guarani não parece ter sido vitoriosa naquele momento, considerando-se as

\footnotetext{
${ }^{34}$ Segundo Meliá, no princípio das Reduções existiam escolas para as meninas. No entanto, estas foram extintas e não se tem notícia de terem sido restabelecidas em algum momento. Bartolomeu Meliá, La lengua guarani del Paraguay: historia, sociedad y literatura, Madri, Editorial MAPFRE, 1992, p. 102.

${ }^{35}$ Sobre os casamentos mistos no continente de São Pedro, ver: Elisa Frühauf Garcia, A integração das populações indígenas nos povoados coloniais no Rio Grande de São Pedro: legislação, etnicidade e trabalho, Niterói, Rio de Janeiro, UFF, 2003 (Dissertação de mestrado), p. 42 e segs.
} 
reiteradas críticas sobre a pouca disposição demonstrada pelos aldeados em aprender e utilizar a língua portuguesa.

Para dimensionar, porém, o sucesso do projeto pombalino, não só em relação à língua, mas também no seu aspecto principal de transformação dos índios em vassalos iguais aos de origem lusitana, não se devem apenas considerar os objetivos claramente expostos no texto da lei, como ainda confrontálos com as repetidas queixas dos administradores e colonos. Estes sempre reclamavam, na correspondência oficial e nas suas memórias, da permanência dos costumes tidos como característicos dos índios, principalmente a língua, a vestimenta e a falta de disciplina para o trabalho, que passaram a funcionar como sinais diacríticos na diferenciação entre os índios e os não índios.

Além disso, o Diretório deve ser apreendido de acordo com os diferentes locais em que foi posto em prática e, nesse sentido, é necessário considerar as especificidades e adaptações realizadas, incluindo, principalmente, as características das populações indígenas às quais foi aplicado. A permanência dos costumes guaranis entre os aldeados é visível em vários aspectos, muito embora alguns destes costumes também tenham se modificado com a experiência na Aldeia e a partir do convívio com os luso-brasileiros. Desta forma, se os índios mantiveram, ao longo da sua vivência na Aldeia, os sinais diacríticos que os diferenciavam do restante da população, foi porque isto era possível naquele momento, no qual eles eram valorizados como vassalos em potencial do Rei Fidelíssimo. Assim, no contexto local, a aparente "incongruência" entre o exposto pelo Diretório e as práticas na Aldeia era o que viabilizava a permanência dos índios em território português, pois aquela realidade, aparentemente desconexa, era fruto de uma barganha constante entre estes e os funcionários reais.

\section{A identidade reafirmada por meio da língua}

A se dar crédito aos relatos dos colonos, parece que a população indígena da Aldeia não se mostrou muito disposta a permitir a mudança do seu idioma. Apesar dos esforços no sentido de impor a língua portuguesa aos índios, estes optaram, enquanto puderam, pela manutenção do idioma guarani. Porém, não se tratava de uma língua guarani que preexistia à chegada dos europeus ao continente americano e se manteve intacta aos contatos. $\mathrm{O}$ idioma guarani foi modificado pela história dos povos indígenas e da sua convivência com os por- 
tugueses e espanhóis. ${ }^{36}$ No entanto, foi a língua por excelência da experiência missioneira, e os índios a trouxeram consigo para a Aldeia. Era um idioma que fazia parte da sua história, vivida e contada por gerações em guarani.

Ao relacionar as línguas das populações nativas ou a língua geral aos costumes "bárbaros e rústicos" dos índios, o texto do Diretório reconhecia a intrínseca relação entre idioma, cultura e identidade. Segundo Peter Burke: "uma das manifestações mais importantes da identidade coletiva é a língua", 37 no sentido em que forma uma comunidade unida pelo mesmo idioma e que se distingue das outras pelo mesmo motivo.

A língua, no entanto, não é um dos elementos fundamentais para a formação de comunidades, pois estas podem existir sem uma uniformidade lingüística, ao mesmo tempo em que comunidades diferentes podem compartilhar um mesmo idioma. Nenhum critério é por si só significativo de diferenças culturais e étnicas, mas estas são construídas a partir da escolha, dentro de um conjunto de especificidades, dos elementos de diferenciação e coesão, entre os quais é comum a língua ter um espaço privilegiado. ${ }^{38}$

Assim, se, de um lado, o texto do Diretório foi perspicaz ao diagnosticar a relação da língua com os costumes dos índios, de outro, talvez não o tenha sido ao propor a sua erradicação por meio da escola e da proibição dos idiomas "nativos". Os grupos étnicos não existem no isolamento, sendo a sua formação originada a partir do contato com outros grupos. Nesse sentido, os sinais de diferenciação são percebidos e hierarquizados durante as relações interétnicas. ${ }^{39}$ Se muitos dos elementos propostos no Diretório não eram em si uma novidade para as populações indígenas da Aldeia, como a escola e os hábitos cristãos, outros o foram, como a mudança de idioma. Durante a sua vivência nas reduções, os contatos dos índios com a sociedade colonial eram facilmente conduzidos a partir do guarani, enquanto língua franca. A sua alocação na Aldeia e a conseqüente obrigatoriedade do uso do português devem ter potencializado as particularidades, ao mesmo tempo em que a língua foi sendo percebida como um elemento diferenciador. Ou seja, ao proibir o idioma

\footnotetext{
${ }^{36}$ Bartolomeu Meliá, op. cit., p. 22-26.

${ }^{37}$ Peter Burke, "Língua e identidade no início da Itália moderna", in A arte da conversação, São Paulo, UNESP, 1995, p. 94.

${ }^{38}$ Fredrik Barth, "Os grupos étnicos e suas fronteiras”, in O guru, o iniciadore outras variações antropológicas, Rio de Janeiro, Contra Capa Livraria, 2000, p. 32.

${ }^{39}$ Fredrik Barth, op. cit., p. 26 e segs.
} 
guarani, o Diretório provavelmente despertou nos índios a percepção de que ele era um aspecto formador da sua identidade. Segundo Burke:

da mesma forma que a consciência de identidade é moldada em situações de contato e conflito, os signos ou emblemas de identidade tornam-se signos somente quando uma outra pessoa tenta eliminá-los. ${ }^{40}$

O Diretório, se, de um lado, colaborou para a instalação dos índios missioneiros no território do Rio Grande, obtendo os almejados vassalos, de outro, também foi agente da construção e permanência das fronteiras étnicas, contribuindo para a consciência que os índios tinham das suas especificidades. Assim, o Diretório obteve os seus vassalos, embora estes não fossem, necessariamente, portugueses.

${ }^{40}$ Peter Burke, op. cit., p. 105. 